\title{
C-Type Lectin-Like Receptors: Head or Tail in Cell Death Immunity
}

\author{
Marion Drouin ${ }^{1,2 \dagger}$, Javier Saenz ${ }^{1 \dagger}$ and Elise Chiffoleau ${ }^{1 *}$ \\ ${ }^{1}$ Université de Nantes, Inserm, Centre de Recherche en Transplantation et Immunologie, UMR 1064, ITUN, Nantes, France, \\ ${ }^{2}$ OSE Immunotherapeutics, Nantes, France
}

C-type lectin-like receptors (CLRs) represent a family of transmembrane pattern recognition receptors, expressed primarily by myeloid cells. They recognize not only pathogen moieties for host defense, but also modified self-antigens such as damage-associated molecular patterns released from dead cells. Upon ligation, CLR signaling leads to the production of inflammatory mediators to shape amplitude, duration and outcome of the immune response. Thus, following excessive injury, dysregulation of these receptors leads to the development of inflammatory diseases. Herein, we will focus on four CLRs of the "Dectin family," shown to decode the

OPEN ACCESS

Edited by:

Sandra J. Van Vliet,

VU University Medical

Center, Netherlands

Reviewed by:

Angel L. Corbi,

Spanish National Research Council

(CSIC), Spain

Mayda Gursel,

Middle East Technical

University, Turkey

*Correspondence:

Elise Chiffoleau

elise.chiffoleau@univ-nantes.fr

†These authors have contributed equally to this work

Specialty section:

This article was submitted to Antigen Presenting Cell Biology,

a section of the journal

Frontiers in Immunology

Received: 29 August 2019

Accepted: 30 January 2020

Published: 18 February 2020

Citation:

Drouin M, Saenz J and Chiffoleau E (2020) C-Type Lectin-Like Receptors:

Head or Tail in Cell Death Immunity.

Front. Immunol. 11:251.

doi: 10.3389/fimmu.2020.00251 immunogenicity of cell death. CLEC9A on dendritic cells links F-actin exposed by dying cells to favor cross-presentation of dead-cell associated antigens to CD8 ${ }^{+} \mathrm{T}^{-}$ cells. Nevertheless, CLEC9A exerts also feedback mechanisms to temper neutrophil recruitment and prevent additional tissue damage. MINCLE expressed by macrophages binds nuclear SAP130 released by necrotic cells to potentiate pro-inflammatory responses. However, the consequent inflammation can exacerbate pathogenesis of inflammatory diseases. Moreover, in a tumor microenvironment, MINCLE induces macrophage-induced immune suppression and cancer progression. Similarly, triggering of LOX-1 by oxidized LDL, amplifies pro-inflammatory response but promotes tumor immune escape and metastasis. Finally, CLEC12A that recognizes monosodium urate crystals formed during cell death, inhibits activating signals to prevent detrimental inflammation. Interestingly, CLEC12A also sustains type-I IFN response to finely tune immune responses in case of viral-induced collateral damage. Therefore, CLRs acting in concert as sensors of injury, could be used in a targeted way to treat numerous diseases such as allergies, obesity, tumors, and autoimmunity.

Keywords: C-type lectin-like receptors, dead cells, sterile inflammation, tissue injury, cross-presentation

\section{INTRODUCTION}

Cell death represents an important process occurring in the natural and physiologic contexts of embryonic development and tissue renewal, or in protection against factors such as disease or localized injury. In contrast to apoptosis, representing an orderly method of removing unwanted cells, necrosis is a more violent form of cell death that ultimately leads to the loss of integrity of the plasma membrane and the release of damage-associated molecular patterns (DAMPs) into the extracellular space (1-10). This induces an inflammatory response that subserves a number of biological functions exerting both positive and negative consequences. Inflammation will lead to rapid delivery of cellular and soluble defenses to the site of death in order to contain the 
injurious process and to help to clear debris and stimulate repair. However, release of anti-microbial molecules, such as reactive oxygen species by myeloid cells can further damage the tissue. Thus, inflammatory response can cause disease particularly in the case of dysregulated or excessive cell death (11). Molecules associated with dying/dead cells are detected by diverse receptors that via particular signaling, impact cell function and determine whether death is immunogenic or tolerogenic. Prominent among death sensors are the members of the C-type lectin receptor superfamily expressed mostly by myeloid cells (12). They constitute transmembrane and soluble receptors containing at least one carbohydrate recognition domain, in the broader sense, a C-type lectin-like domain (CTLD) (13-16). Via this domain, these receptors usually bind carbohydrates through a $\mathrm{Ca} 2^{+}$dependent conserved motif. However, some of them lack the $\mathrm{Ca}^{2}{ }^{+}$binding site and are called C-Type Lectin-Like Receptors (CLRs). CLRs were shown to play an important role in both innate and adaptive immunity, particularly the ones from the "Dectin" family whose genes are localized in the telomeric region of the natural killer cluster $(17,18)$. Upon ligation, CLRs not only serve as antigen-uptake receptors for internalization and presentation to $\mathrm{T}$ cells, but also trigger multiple signaling pathways leading to NF- $\kappa$ B, typeI interferon (IFN) and/or inflammasome activation (17-20). CLRs are usually classified as activating or inhibitory receptors, based on their intracellular signaling motifs (21-23). They can have a classical immunoreceptor tyrosine-based activating motif (ITAM) constituted by YXXL tandem repeats in the intracellular tail or can interact with ITAM-containing adaptor proteins, such as $\mathrm{Fc}$ receptor $\gamma(\mathrm{FcR} \gamma)$ chain $(21,24)$. Other CLRs contain an hemi-ITAM motif composed of a single tyrosine within an YXXL motif $(20,25)$. Upon ligation, tyrosine(s) present in the ITAM or hemITAM motifs are phosphorylated, allowing the recruitment of SYK family kinases and the formation of the Card9/Bcl10/Malt1 complex (19, 21, 26-29). This leads to activation of NF-кB pathway and various cellular responses such as the production of reactive oxygen species (ROS) and the expression of diverse cytokines and chemokines to regulate both innate and adaptive immune responses $(19,28-33)$. In contrast, some CLRs contain an immunoreceptor tyrosine-based inhibitory motif (ITIM) that induces the recruitment of tyrosine phosphatases such as Src homology region 2 domain-containing phosphatase (SHP) -1 or -2 , to negatively regulate the activity of activating signaling pathways (34-37). At last, some CLRs have neither ITAM nor ITIM domains and their signaling is either uncharacterized or utilizes alternative pathways such as via the serine/threonine kinase RAF-1 $(17,35,38,39)$. However, classification of CLRs as activating or inhibitory receptors is not as simple. A same CLR can according to the ligand (physical nature, affinity, avidity) or the environment, integrate distinct positive and negative signals, to shape immune response in complex scenarios (37). In addition, sensing of tissue damage by CLRs can complement detection of pathogens. This crosstalk in CLR recognition and signaling of both pathogen-associated molecular patterns (PAMPs) released following viral infections and DAMP from collateral injured cells may ensure microbial control while preserving integrity of the infected organs (40). Moreover, several studies have highlighted the fundamental role of these receptors during excessive cell death induced by sterile inflammation and their dysregulations were shown to lead to the development of inflammatory and auto-immune diseases (40-42). As shown herein in Table 1 and Figure 1, we will

TABLE 1 | C-type lectin-like receptors sensing DAMPs.

\begin{tabular}{|c|c|c|c|c|c|}
\hline & Gene name & Expression & DAMP ligand/s & Functional effects & Associated diseases \\
\hline $\begin{array}{l}\text { CLEC8A, OLR-1, } \\
\text { LOX-1 }\end{array}$ & $\begin{array}{l}\text { OLR1 }(\mathrm{Hs}) \\
\text { Olr1 }(\mathrm{Mm})\end{array}$ & $\begin{array}{l}\mathrm{EC}, \mathrm{mDC}, \mathrm{moDC}, \mathrm{B}, \mathrm{M} \varnothing \\
\text { (Hs and } \mathrm{Mm})\end{array}$ & $\begin{array}{l}\text { oxLDL, oxHDL, } \\
\text { apoptotic bodies, } \\
\text { phospha-tidylserine }\end{array}$ & $\begin{array}{l}\uparrow \text { ROS, corpse uptake; ag } \\
\text { capture and presentation }\end{array}$ & $\begin{array}{l}\text { Promotes atherosclerosis, } \\
\text { hypertension, diabetes, } \\
\text { metabolic syndrome, coronary } \\
\text { artery diseases and cancers }\end{array}$ \\
\hline $\begin{array}{l}\text { CLEC4E, MINCLE, } \\
\text { CLECSF9 }\end{array}$ & $\begin{array}{l}\text { CLEC4E }(\mathrm{Hs}) \\
\text { Clec4e }(\mathrm{Mm})\end{array}$ & MØ, PMN (Hs and Mm) & $\begin{array}{l}\text { SAP130, } \\
\beta \text {-GlcCer, cholesterol } \\
\text { sulfate and crystal }\end{array}$ & $\begin{array}{l}\text { Necrotic cell uptake, } \\
\uparrow T N F \alpha, \text { IL-6, CXCL1, IL-1, } \\
\text { MIP- } 1 \alpha / \beta, \text { MIP-2 }\end{array}$ & $\begin{array}{l}\text { Promotes obesity, rheumatoid } \\
\text { arthritis, allergic contact } \\
\text { dermatitis, ischemic stroke, } \\
\text { traumatic brain injury, hepatitis, } \\
\text { sepsis and multiple sclerosis }\end{array}$ \\
\hline $\begin{array}{l}\text { CLEC12A, MICL, } \\
\text { DCAL-2, } \\
\text { CLL-1, CD371 }\end{array}$ & $\begin{array}{l}\text { CLEC12A (Hs) } \\
\text { Clec12a (Mm) }\end{array}$ & $\begin{array}{l}\text { CMP, GMP, MEP, MØ, Bs, } \\
\text { Gr, Mo, DC (Hs and Mm) }\end{array}$ & $\begin{array}{l}\text { Mono-sodium } \\
\text { urate crystals }\end{array}$ & $\begin{array}{l}\text { Necrotic cell ag } \\
\text { cross-presentation, SYK } \\
\text { inhibition, } \\
\downarrow \text { CXCL1/10 and excessive } \\
\text { neutrophil infiltration } \\
\downarrow \text { ROS, IL-8 } \\
\uparrow \text { Type-I IFN }\end{array}$ & Reduces gout arthritis \\
\hline $\begin{array}{l}\text { CLEC9A, DNGR-1, } \\
\text { CD370 }\end{array}$ & $\begin{array}{l}\text { CLEC9A }(\mathrm{Hs}) \\
\text { Clec9a }(\mathrm{Mm})\end{array}$ & $\begin{array}{l}\text { CDPs; XCR1+ DC, pDC } \\
(\mathrm{Mm}) \\
\mathrm{BDCA3}+\mathrm{DC}(\mathrm{Hs})\end{array}$ & F-actin & $\begin{array}{l}\text { Necrotic cell ag } \\
\text { cross-presentation, } \\
\downarrow \text { MIP-2 and excessive } \\
\text { neutrophil infiltration }\end{array}$ & $\begin{array}{l}\text { Promotes atherosclerosis and } \\
\text { pancreatitis }\end{array}$ \\
\hline
\end{tabular}

CLRs reported to interact with DAMPs and discussed in this review. Hs, Homo sapiens; Mm, Mus musculus; CDPs, common DC progenitors; CMP, common myeloid progenitor; GMP, granulocyte myeloid progenitors; MEP, megakaryocyte-erythroid progenitors; Gr, Granulocytes; Bs, Basophils; MØ, Macrophages; Mo, Monocytes; B, B cells; EC, Endothelial cells; PMNs, polymorphonuclear leukocyte; moDCs, monocyte-derived DCs; mDC, myeloid DC; pDC, plasmacytoid DC; ag, antigen. 
present a brief overview of the four CLRs of the dectin family largely described to decode the immunogenicity of cell death, thereby representing important medical therapeutic targets. This list is however not exhaustive. A recent study demonstrates that CLEC7A on DCs binds to annexins on apoptotic cells and induces by a selective SYK phosphorylation, the production of ROS to prevent auto-immune disease development (43).

\section{CLEC8A (LOX-1, OLR-1)}

The lectin-like oxidized low-density lipoprotein receptor-1 (LOX-1) is a homodimer expressed by macrophages, DCs, B cells, endothelial cells, activated platelets and smooth muscle cells $(17,44-53)$. Its basal expression is relatively low but is dynamically upregulated by pro-inflammatory cytokines, stress, oxidized low-density lipoprotein (oxLDL), angiotensin II and endothelin $(54,55)$. LOX-1 is involved in numerous physiological functions and binds a broad spectrum of structurally distinct ligands including oxLDL (46), oxidized hypochlorite modified high-density lipoprotein (oxHDL) (56), phosphatidylserine (PS) (52), apoptotic bodies (57), advanced glycation end-products (AGEs) (58), bacteria (59), heat shock proteins 60 (Hsp60) (60), and platelets (61). LOX-1 has no known enzymatic or catalytic activity in its cytoplasmic tail and may require interaction with protein(s) for intracellular signaling. Following uptake of its ligand, LOX-1 induces pro-inflammatory signaling pathways leading to production of ROS, secretion of pro-inflammatory cytokines and induction of apoptosis signals (Table 1 and Figure 1). Thus, LOX-1 plays a pivotal role in the development of atherosclerosis, by inducing oxLDL uptake, lipidosis, foam cell generation and ultimately atheroma plaque formation $(62,63)$. This OxLDL/LOX-1 axis was also shown to play a role in cartilage degeneration during age-related osteoarthritis progression in the murine knee (64). Similarly, the triggering of LOX-1 by AGEs, contributes to diabetic complications such as atherosclerosis (65, 66). LOX-1 was also reported to play a key role in endothelial cell phagocytosis of apoptotic/aged cells due to the ability to recognize the exposure of PS on the surface of apoptotic cells (57). Interestingly, LOX-1 can be cleaved as a soluble form released in the circulation (67). This soluble form is overexpressed in patients with hypertension, diabetes, metabolic syndrome, and coronary artery diseases $(58,68)$, making soluble LOX1 a non-invasive biomarker of disease. Importantly, numerous studies described the importance of LOX-1 in the progression of distinct types of cancer. Thus, a high expression of LOX1 is correlated with a worse prognosis in patients suffering from gastric (69), colorectal (70), or prostate (71) cancer. Functionally, the triggering of LOX-1 by oxLDL was shown to induce TNF- $\alpha$ expression, tumor angiogenesis and tumor cell trans-endothelial migration and metastasis in prostate or breast cancers $(71,72)$. Interestingly, a high expression of LOX-1 was reported on polymorphonuclear myeloid-derived suppressor cells from peripheral blood and tumor of cancer patients (up to 5-50\%), whereas its expression is almost undetectable on blood neutrophils from healthy donors (73). Therefore, expression of LOX-1 on these suppressive cells that is due to endoplasmic reticulum stress and lipid metabolism, may represent a specific therapeutic target in cancer. Besides, LOX-1 on DCs was shown to bind to Hsp to potentiate cross-presentation of chaperoned peptides (51) and apoptotic cells-coupled antigens (74) to cytotoxic $\mathrm{CD}^{+}{ }^{+} \mathrm{T}$ cells. In addition, LOX-1 on B cells was shown to promote $\mathrm{B}$ cell differentiation into class-switched plasmablasts, their exit from germinal centers and their migration toward local mucosa and skin (48). Although the specific ligands remain to be characterized, this study demonstrates that triggering of LOX-1 could be applied for the design of new vaccines.

\section{CLEC4E (MINCLE, CLECSF9)}

CLEC4E, more commonly known as MINCLE (Macrophageinducible C-type lectin), associates with the FcR $\gamma$ chain, an ITAM-containing adapter. In addition, it forms a functional heterodimer with Macrophage C-type Lectin (MCL). Through this complex, MINCLE is translocated to the plasma membrane and benefits the endocytic capacity of MCL to mediate an efficient phagocytosis. Moreover, through this complex, both receptors increase their affinity and specificity toward their ligands (75). MINCLE is expressed by antigen-presenting cells including macrophages, neutrophils, DCs and B cells (76). Its expression is induced by several inflammatory stimuli and stresses, such as lipopolysaccharide (LPS), tumor necrosis factor (TNF), IL-6 and saturated fatty acids (76-79) and was found over-expressed in numerous inflammatory diseases (77, 80-86). Interestingly, a polymorphism in this receptor has been linked to protection against rheumatoid arthritis in humans (87). MINCLE is largely described to recognize glycolipids from pathogens (88), but binds also ligands released by dead cells such as spliceosomeassociated protein 130 (SAP130) $(21,89), \beta$-glucosylceramide $(\beta$ GlcCer) (90), cholesterol sulfate and crystals $(82,91)$ (Table 1 and Figure 1). This triggers the recruitment of SYK and the activation of NF- $\mathrm{B}$, mitogen-activated protein kinase (MAPK), activator protein 1 (AP-1) or nuclear factor of activated T cells (NFAT) and downstream transcription of inflammatory genes $(21,88$, 92-97). MINCLE induces the expression of several cytokines and chemokines such as TNF- $\alpha$, IL-6, MIP-2, and CXCL1 (21, $28,29)$. In vivo, MINCLE was shown to potentiate neutrophil infiltration following tissue damage induced by non-homeostatic cell death (21). Indeed, authors demonstrated that administration of anti-MINCLE blocking antibody following whole-body irradiation reduces MIP-2 production by thymic macrophages and consequently neutrophil infiltration. It remains to determine whether the recruitment of inflammatory cells induced by MINCLE is beneficial or exacerbates tissue damage. However, in an intriguing way, no such effect on neutrophilic inflammatory responses was observed in MINCLE-deficient mice following intra-peritoneal injection of necrotic cells or in response to liver cell necrosis induced by acetaminophen (98). One could speculate that this specific role of MINCLE on neutrophils may depend on the model or be due to some compensatory change with other dead-cell receptors in MINCLE-deficient mice. Alternatively, as neutrophils also express MINCLE, the use of antibodies may have exerted pleotropic effects by directly 
DAMPs

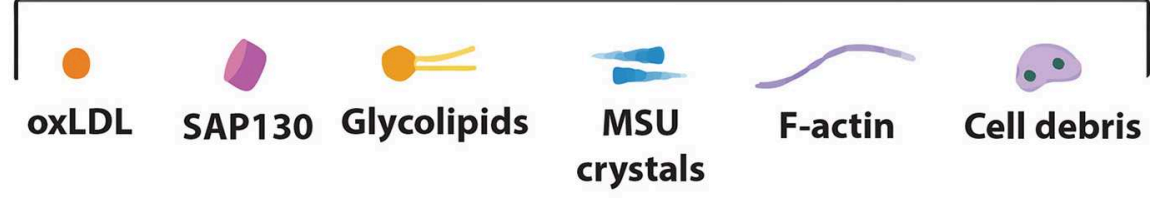

crystals
Apoptotic/Necrotic cells

8)
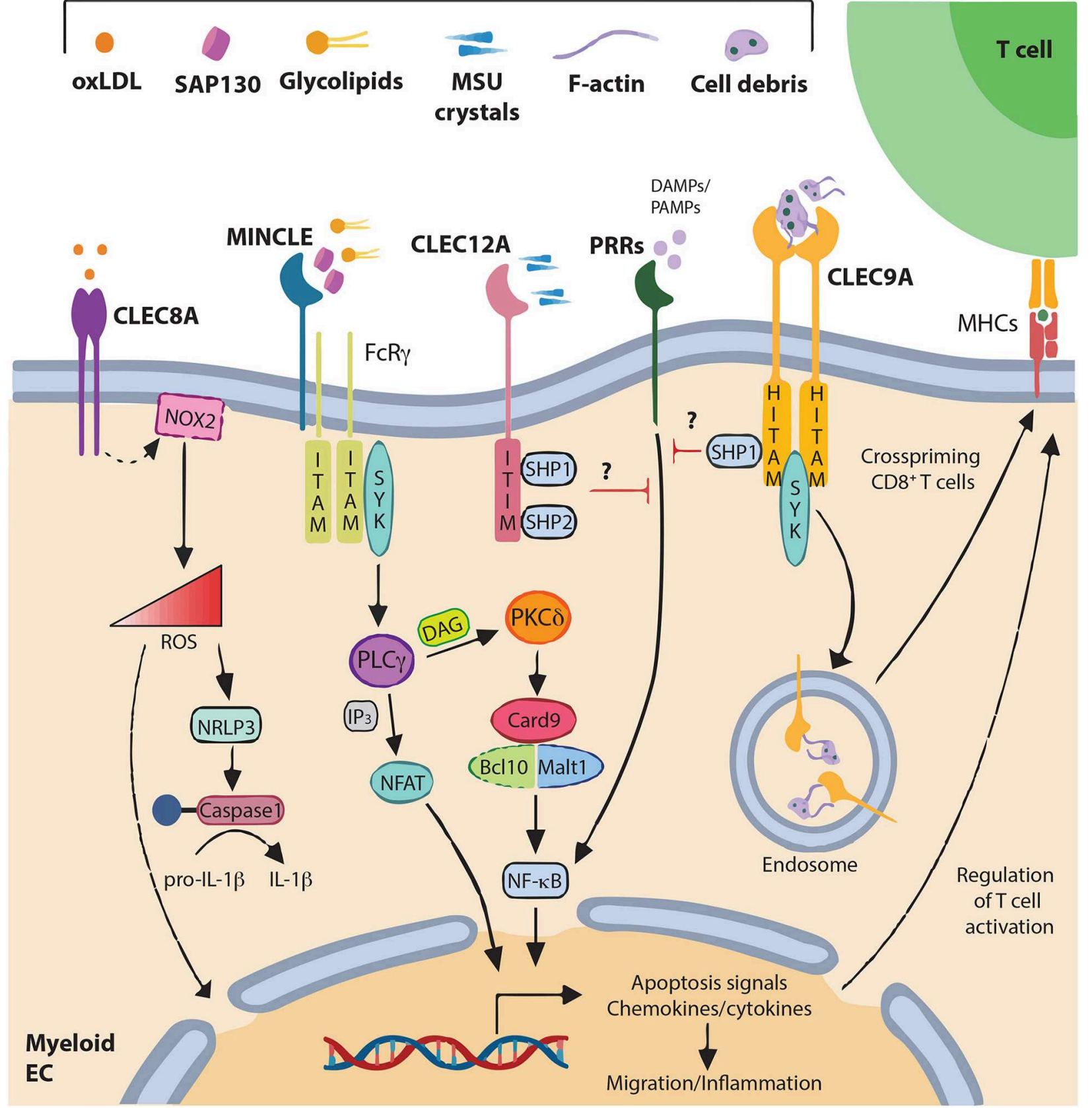

FIGURE 1 | DAMPs recognition by C-type lectin-like receptors and signaling pathways C-type lectin-like receptors (CLRs) of the "Dectin family" recognize not only pathogen-associated molecular patterns (PAMPs), but also various self-derived ligands such as damage-associated molecular patterns (DAMPs). This recognition triggers activation of immune-receptor tyrosine-based activation motif (ITAM), leading to the recruitment and activation of SYK family kinases. Subsequent activation of the Card9-Bcl10-Malt1 complex through SYK induces NF-KB activation and gene transcription of various chemokines and cytokine (CLEC4E alias MINCLE). Alternatively, CLEC4E can also signal through PLC $\gamma 2$ to induce the calcineurin/NFAT pathway. Alternatively, immune response can be regulated through increase of ROS and IL-1 $\beta$ production (CLEC8A) modifying gene expression and releasing ROS to the extracellular matrix. By contrast, activation of immune-receptor tyrosine-based inhibition motif (ITIM) induces the recruitment and activation of protein tyrosine phosphatases such as SHP-1 and SHP-2 and the dephosphorylation of activation motifs to inhibit cellular activation mediated by other pattern-recognition receptors (PRRs) (CLEC12A). CLEC9A, via Hemi-ITAM (HITAM) plays a key role in $\mathrm{CD}^{+} \mathrm{T}$ cell cross-priming. In addition, CLEC9A can activate SHP-1 to exert inhibitory feedback and restrain excessive immune response. 
targeting or depleting neutrophils (98). Although MINCLE contributes to inflammation and immunity to contain the insult and initiate tissue repair, it can amplify collateral tissue damage and was therefore demonstrated to be implicated in numerous inflammatory diseases such as obesity, rheumatoid arthritis, allergic contact dermatitis, ischemic stroke, traumatic brain injury, hepatitis, sepsis, and multiple sclerosis $(77,80-$ 86). Besides, MINCLE recognizes cholesterol crystals abundantly present in atherosclerotic plaques, triggering in macrophages the production of pro-inflammatory molecules (91). MINCLE was also shown to play a specific role on plasmacytoid DCs in skin allergies by recognizing cholesterol sulfate and inducing secretion of pro-inflammatory mediators such as IL- $1 \alpha$, IL- $1 \beta$, MIP- $1 \alpha$, and MIP-1 $\beta$ (82). Furthermore, $\beta$-GlcCer whose accumulation leads to the systemic inflammation of Gaucher disease, was also characterized as a ligand for MINCLE, able to potentiate acquired immune response (90). Thus, MINCLE, via its high expression on M1-type macrophages and its ability to sense dead cells was also shown to be an important mediator of additional inflammatory diseases such as obesity and acute kidney injury $(77,78,99,100)$. In addition, MINCLE, by initiating inflammation, participates in the pathogenesis of cerebral ischemic stroke (83) and neuropathic pain by sensing damaged nerves (101). In cancer, the recruitment of macrophages induced by MINCLE appeared to be detrimental in a mouse model of pancreatic ductal adenocarcinoma. Authors demonstrated that ligation of MINCLE by its ligand SAP130, both highly expressed by inflammatory cells from tumors, promotes adaptive immune suppression and drives necrosomeinduced accelerated oncogenesis (102). Interestingly, MINCLE not only acts as an activating (ITAM) receptor but can also act as an inhibitory-ITAM (ITAMi) receptor. Indeed, following recognition of the pathogen moieties of Leishmania, MINCLE shifts to an ITAMi configuration that impairs DC activation. Thus, ITAMi configuration exploited by a pathogen for immune evasion, may represent a paradigm for ITAM-coupled receptors sensing self and non-self $(103,104)$. As DAMPs are "mimics" of PAMPs, it will be interesting to investigate whether such a ligand-dependent dual sensing pathway exists also for a DAMP counterpart.

\section{CLEC12A (MICL, DCAL2, CLL-1, OR CD371)}

CLEC12A, is a homodimer expressed mostly by myeloid cells such as neutrophils, monocytes, macrophages and DCs, and is considered as a marker of acute myeloid leukemia blasts $(22,105-111)$. CLEC12A expression is downregulated by inflammatory stimuli $(108,112)$ and its ITIM domain recruits the tyrosine phosphatases SHP-1 and SHP-2 to counteract activating positive regulatory signals (22). CLEC12A was the first inhibitory receptor of the dectin cluster of genes described to sense a DAMP (Table 1 and Figure 1). It binds monosodium urate (MSU) crystal formed by crystallization of soluble uric acid following contact with extracellular sodium ions, when cells are dying. Thus, CLEC12A deficient mice, after in vivo challenge with MSU or necrotic cells or after radiation-induced thymocyte killing, exhibit hyperinflammatory responses (105). Functionally, CLEC12A limits the neutrophil recruitment in tissue following cell damage by inhibiting CXCL1 and CXCL10 production and by limiting ROS and IL8 production by neutrophils $(105,113)$. Therefore, by sensing cell death, CLEC12A represents an immune checkpoint that provides negative feedback mechanism for immunoregulation and protection of tissues from an overexuberant inflammatory response. As deposition of MSU crystal is observed in a variety of inflammatory responses such as in the arthritis disease "gout," $(105,114)$, the development of a selective agonist for CLEC12A may represent a valuable therapeutic challenge. Interestingly, a link between CLEC12A and the type-I IFN response that is important for host immunity against viral infection, was recently demonstrated. Authors elegantly showed that following viral infection, CLEC12A triggered by MSU released by host dead cells, positively activates a type-I IFN response thereby amplifying anti-viral immune response (115). By sensing tissue integrity, CLEC12A can therefore finely modulate the equilibrium between infection-driven inflammation and control of pathogens. Authors proposed that as prolonged type-I IFN signaling during chronic virus infection facilitates virus persistence by inducing negative immune regulators, CLEC12A inhibition may be clinically beneficial in cases of persistent infection $(116,117)$. Similarly, the inhibitory receptor DCIR was shown to sustain type-I IFN signaling in DCs through interaction with an unidentified endogenous ligand(s) (118). Although both of these CLRs contain an ITIM in their cytoplasmic tail, and are thought to act as negative regulators of immune cell signaling, these results suggest that ITIM can somehow activate, rather than inhibit, some signaling pathways $(22,118)$. Whether these receptors deliver a signal on their own through the ITIM motif or require a co-receptor will need further molecular dissection. In fact, it will be interesting to investigate whether ITIMcoupled CLR-deficient animals develop autoimmune diseases as a consequence of impaired type-I IFN signaling, thereby increasing IL-12 production and Th1 differentiation (118). Interestingly, CLEC12A-deficient mice were reported to develop exacerbated arthritis in a collagen antibody-induced model characterized by cell death in the synovium (114). Astonishingly, authors proposed that during arthritis development, CLEC12A acts as an autoantigen that modulates threshold of myeloid cell activation. To support their hypothesis, they mentioned that this receptor is the target of autoantibodies in a subset of rheumatoid arthritis patients (114). Besides, several studies demonstrated in both mice and humans that CLEC12A on DCs serves as a specific target for antigen delivery to enhance $\mathrm{CD} 8^{+} \mathrm{T}$ cell and antibody responses $(106,110)$.

\section{CLEC9A (CD370, DNGR-1, UNQ9341)}

CLEC9A is a homodimer highly expressed on common dendritic cell (DC) progenitors (CDPs) and type 1 conventional DCs $(\mathrm{cDC} 1)\left(\mathrm{XCR}^{+}{ }^{+}\right.$in mouse and $\mathrm{BDCA}^{+}{ }^{+}$counterparts in human) (119-124). CLEC9A, whose expression is lost after Toll-like receptor-mediated maturation (122), binds to a fibrous polymer of actin, termed F-actin, an evolutionarily conserved ligand from yeast to mammals exposed by pathogens and dead cells $(125,126)$ (Table 1 and Figure 1). CLEC9A 
has a hemi-ITAM cytoplasmic tail with a highly conserved tyrosine that upon phosphorylation allows binding to SYK (23). Following F-actin recognition, CLEC9A signaling does not influence cell debris uptake nor maturation of dendritic cells (127). However, CLEC9A diverts phagocytosed dead cell cargo to a non-degradative recycling endosome compartment thereby facilitating cross-presentation of the dead-cell-associated antigens to $\mathrm{CD}^{+} \mathrm{T}$ cells (23). Myosin II, an actin-associated motor protein, potentiates the binding of CLEC9A to Factin by facilitating co-operative binding of the two CTLD domains of the CLEC9A dimer, thereby rendering the crosspresentation more efficient (128). Thus, CLEC9A plays an important function in $\mathrm{CD}^{+} \mathrm{T}$ cell cross-priming during herpes virus infection $(127,129)$ and specifically induces optimal generation of tissue-resident memory $\mathrm{T}$ cells during influenza infection (130). The targeting of CLEC9A with tumor-expressed peptides together with adjuvant was shown to induce efficient cross-priming of $\mathrm{CD}^{+} \mathrm{T}$ cells and to control tumor immunity in a mouse model of melanoma (124). Moreover, during atherosclerosis, CLEC9A on cDC1, activated by the accumulation of necrotic cell debris, leads to disease progression by inducing macrophage and T-cell infiltration within lesions and by decreasing the expression of the anti-inflammatory cytokines TGF $\beta$ and IL-10 (131). Interestingly, in addition to its role in cross-presentation, CLEC9A exerts also an inhibitory feedback mechanism following tissue damage by activating the negative regulatory signal SHP-1 to dampen neutrophil-mediated immunopathology (132) (Figure 1). In this elegant study, authors showed that the lack of CLEC9A specifically in $\mathrm{CDC1}$ increases the production of MIP-2 and consequently amplifies the recruitment of neutrophils and collateral tissue damage in mouse models of sterile and infectious injury (132). However, the mechanism by which Factin could, according to the context, trigger opposing signals through SYK or SHP-1 remains to be elucidated. Taken together, these results suggest that the targeting of CLEC9A to regulate

\section{REFERENCES}

1. Lockshin RA, Williams CM. Programmed cell death-II. endocrine potentiation of the breakdown of the intersegmental muscles of silkmoths. J Insect Physiol. (1964) 10:643-9. doi: 10.1016/0022-1910(64) 90034-4

2. Lockshin RA, Williams CM. Programmed cell death-I. cytology of degeneration in the intersegmental muscles of the Pernyi silkmoth. $J$ Insect Physiol. (1965) 11:123-33. doi: 10.1016/0022-1910(65)9 0099-5

3. Kerr JF. A histochemical study of hypertrophy and ischaemic injury of rat liver with special reference to changes in lysosomes. J Pathol Bacteriol. (1965) 90:419-35. doi: 10.1002/path.1700900210

4. Schweichel J-U, Merker H-J. The morphology of various types of cell death in prenatal tissues. Teratology. (1973) 7:253-66. doi: 10.1002/tera.14200 70306

5. Kroemer G, El-Deiry WS, Golstein P, Peter ME, Vaux D, Vandenabeele P, et al. Classification of cell death: recommendations of the nomenclature committee on cell death. Cell Death Differ. (2005) 12:1463-7. doi: $10.1038 /$ sj.cdd. 4401724

6. Chen GY, Nuñez G. Sterile inflammation: sensing and reacting to damage. Nat Rev Immunol. (2010) 10:826-37. doi: 10.1038/nri2873 the antigenicity of dead or virus-infected cells, could have a clinical therapeutic impact for vaccination, infection and sterile inflammation.

\section{CONCLUSION}

To conclude, we discussed in this mini review the recent studies that widened the array of identified responses elicited by these receptors and that shed light on the physiological and pathological functions of CLR in response to cell death. By sensing cell death, CLRs seem to protect against potential danger to cellular stress and excessive or deregulated cell death caused by non-infectious or infectious insults $(133,134)$. CLRs can therefore be considered as new immune checkpoint pathways acting as a safeguard to regulate the powerful and potentially harmful immune reactions and to prevent the accidental triggering of responses against the host's own tissues. As dysregulation of these checkpoint pathways induces development of diverse pathologies such as auto-immune diseases or cancers (40-42), understanding the mechanisms by which CLRs are triggered, beyond cell death, can pave the way for future targeting therapies $(42,134-136)$.

\section{AUTHOR CONTRIBUTIONS}

All authors listed have made a substantial, direct and intellectual contribution to the work, and approved it for publication.

\section{ACKNOWLEDGMENTS}

We are grateful to the support by the LIGUE and the National Research Agency (ANR) for French government financial support $y$ the IHU-Cesti project and the LabEX IGO programs (ANR-10-IBHU-005, ANR-11-LABX-0016-01, and ANR generique PRCE 2018).

7. Shi Y, Evans JE, Rock KL. Molecular identification of a danger signal that alerts the immune system to dying cells. Nature. (2003) 425:516-21. doi: 10.1038/nature01991

8. Land W, Schneeberger H, Schleibner S, Illner WD, Abendroth D, Rutili G, et al. The beneficial effect of human recombinant superoxide dismutase on acute and chronic rejection events in recipients of cadaveric renal transplants. Transplantation. (1994) 57:211-7. doi: 10.1097/00007890-199401001-00010

9. Matzinger P. Tolerance, danger, and the extended family. Annu Rev Immunol. (1994) 12:991-1045. doi: 10.1146/annurev.iy.12.040194.005015

10. Seong SY, Matzinger P. Hydrophobicity: an ancient damage-associated molecular pattern that initiates innate immune responses. Nat Rev Immunol. (2004) 4:469-78. doi: 10.1038/nri1372

11. Robbins SL, Stanley L, Kumar V, Cotran RS. Chap 1: Cellular responses to stress and toxic insults: adaptation, injury, and death. In: Schmitt W, editor. Robbins and Cotran Pathologic Basis of Disease. Philadelphia, PA: Saunders/Elsevier (2010). p. 6-11.

12. Sancho D, Reis e Sousa C. Sensing of cell death by myeloid C-type lectin receptors. Curr Opin Immunol. (2013) 25:46-52. doi: 10.1016/j.coi.2012.12.007

13. Drickamer K. C-type lectin-like domains. Curr Opin Struct Biol. (1999) 9:585-90. doi: 10.1016/S0959-440X(99)00009-3 
14. Drickamer K. Evolution of $\mathrm{Ca}(2+)$-dependent animal lectins. Prog Nucleic Acid Res Mol Biol. (1993) 45:207-32. doi: 10.1016/S0079-6603(08)60870-3

15. Drickamer K, Fadden AJ. Genomic analysis of C-type lectins. Biochem Soc Symp. (2002) 69:59-72. doi: 10.1042/bss0690059

16. Zelensky AN, Gready JE. Comparative analysis of structural properties of the C-type-lectin-like domain (CTLD). Proteins Struct Funct Genet. (2003) 52:466-77. doi: 10.1002/prot.10626

17. Huysamen C, Brown GD. The fungal pattern recognition receptor, Dectin1, and the associated cluster of C-type lectin-like receptors. FEMS Microbiol Lett. (2009) 290:121-8. doi: 10.1111/j.1574-6968.2008.01418.x

18. Kerscher B, Willment JA, Brown GD. The Dectin-2 family of Ctype lectin-like receptors: an update. Int Immunol. (2013) 25:271-7. doi: 10.1093/intimm/dxt006

19. Dambuza IM, Brown GD. C-type lectins in immunity: recent developments. Curr Opin Immunol. (2015) 32:21-7. doi: 10.1016/j.coi.2014.12.002

20. Robinson MJ, Sancho D, Slack EC, LeibundGut-Landmann S, Reis e Sousa C. Myeloid C-type lectins in innate immunity. Nat Immunol. (2006) 7:1258-65. doi: 10.1038/ni1417

21. Yamasaki S, Ishikawa E, Sakuma M, Hara H, Ogata K, Saito T. Mincle is an ITAM-coupled activating receptor that senses damaged cells. Nat Immunol. (2008) 9:1179-88. doi: 10.1038/ni.1651

22. Marshall AS, Willment JA, Lin H-H, Williams DL, Gordon S, Brown GD. Identification and characterization of a novel human myeloid inhibitory C-type lectin-like receptor (MICL) that is predominantly expressed on granulocytes and monocytes. J Biol Chem. (2004) 279:14792-802. doi: 10.1074/jbc.M313127200

23. Sancho D, Joffre OP, Keller AM, Rogers NC, Martínez D, Hernanz-Falcón P, et al. Identification of a dendritic cell receptor that couples sensing of necrosis to immunity. Nature. (2009) 458:899-903. doi: 10.1038/nature07750

24. Gibbins JM, Okuma M, Farndale R, Barnes M, Watson SP. Glycoprotein $\mathrm{VI}$ is the collagen receptor in platelets which underlies tyrosine phosphorylation of the Fc receptor $\gamma$-chain. FEBS Lett. (1997) 413:255-9. doi: 10.1016/S0014-5793(97)00926-5

25. Osorio F, Reis e Sousa C. Myeloid C-type lectin receptors in pathogen recognition and host defense. Immunity. (2011) 34:651-64. doi: 10.1016/j.immuni.2011.05.001

26. Mócsai A, Ruland J, Tybulewicz VL. The SYK tyrosine kinase: a crucial player in diverse biological functions. Nat Rev Immunol. (2010) 10:387-402. doi: $10.1038 /$ nri2765

27. Ostrop J, Jozefowski K, Zimmermann S, Hofmann K, Strasser E, Lepenies B, et al. Contribution of MINCLE-SYK signaling to activation of primary human APCs by mycobacterial cord factor and the novel adjuvant TDB. J Immunol. (2015) 195:2417-28. doi: 10.4049/jimmunol.15 00102

28. Strasser D, Neumann K, Bergmann H, Marakalala MJ, Guler R, Rojowska A, et al. Syk kinase-coupled C-type lectin receptors engage protein kinase $\mathrm{C}-\sigma$ to elicit Card9 adaptor-mediated innate immunity. Immunity. (2012) 36:32-42. doi: 10.1016/j.immuni.2011.11.015

29. Roth S, Bergmann H, Jaeger M, Yeroslaviz A, Neumann K, Koenig PA, et al. Vav proteins are key regulators of Card9 signaling for innate antifungal immunity. Cell Rep. (2016) 17:2572-83. doi: 10.1016/j.celrep.2016. 11.018

30. Gross O, Gewies A, Finger K, Schäfer M, Sparwasser T, Peschel C, et al. Card9 controls a non-TLR signalling pathway for innate anti-fungal immunity. Nature. (2006) 442:651-6. doi: 10.1038/nature04926

31. Gringhuis SI, Den Dunnen J, Litjens M, Van Der Vlist M, Wevers B, Bruijns SCM, et al. Dectin-1 directs $\mathrm{T}$ helper cell differentiation by controlling noncanonical NF-jB activation through Raf-1 and Syk. Nat Immunol. (2009) 10:203-13. doi: 10.1038/ni.1692

32. Drummond RA, Brown GD. Signalling C-Type lectins in antimicrobial immunity. PLoS Pathog. (2013) 9:e1003417. doi: 10.1371/journal.ppat. 1003417

33. Saijo S, Fujikado N, Furuta T, Chung SH, Kotaki H, Seki K, et al. Dectin1 is required for host defense against Pneumocystis carinii but not against Candida albicans. Nat Immunol. (2007) 8:39-46. doi: 10.1038/ni1425

34. Kerrigan AM, Brown GD. Syk-coupled C-type lectin receptors that mediate cellular activation via single tyrosine based activation motifs. Immunol Rev. (2010) 234:335-52. doi: 10.1111/j.0105-2896.2009.00882.x
35. Plato A, Willment JA, Brown GD. C-Type lectin-like receptors of the dectin-1 cluster: ligands and signaling pathways. Int Rev Immunol. (2013) 32:134-56. doi: 10.3109/08830185.2013.777065

36. Chiffoleau E. C-Type lectin-like receptors as emerging orchestrators of sterile inflammation represent potential therapeutic targets. Front Immunol. (2018) 9:227. doi: 10.3389/fimmu.2018.00227

37. del Fresno C, Iborra S, Saz-Leal P, Martínez-López M, Sancho D. Flexible signaling of myeloid C-type lectin receptors in immunity and inflammation. Front Immunol. (2018) 9: 804. doi: 10.3389/fimmu.2018.00804

38. Sancho D, Reis e Sousa C. Signaling by myeloid C-type lectin receptors in immunity and homeostasis. Annu Rev Immunol. (2012) 30:491-529. doi: 10.1146/annurev-immunol-031210-101352

39. Geijtenbeek TBH, Gringhuis SI. Signalling through C-type lectin receptors: shaping immune responses. Nat Rev Immunol. (2009) 9:465-79. doi: $10.1038 /$ nri2569

40. García-Vallejo JJ, Van Kooyk Y. Endogenous ligands for C-type lectin receptors: the true regulators of immune homeostasis. Immunol Rev. (2009) 230:22-37. doi: 10.1111/j.1600-065X.2009.00786.x

41. Cambi A, Figdor C. Necrosis: C-Type lectins sense cell death. Curr Biol. (2009) 19:R375-8. doi: 10.1016/j.cub.2009.03.032

42. Yan H, Kamiya T, Suabjakyong P, Tsuji NM. Targeting C-type lectin receptors for cancer immunity. Front Immunol. (2015) 6:408. doi: 10.3389/fimmu.2015.00408

43. Bode K, Bujupi F, Link C, Hein T, Zimmermann S, Peiris D, et al. Dectin-1 binding to annexins on apoptotic cells induces peripheral immune tolerance via NADPH oxidase-2. Cell Rep. (2019) 29:4435-46.e9. doi: 10.1016/j.celrep.2019.11.086

44. Yamanaka S, Zhang XY, Miura K, Kim S, Iwao H. The human gene encoding the lectin-type oxidized LDL receptor (OLR1) is a novel member of the natural killer gene complex with a unique expression profile. Genomics. (1998) 54:191-9. doi: 10.1006/geno.1998.5561

45. Nickel T, Schmauss D, Hanssen H, Sicic Z, Krebs B, Jankl S, et al. oxLDL uptake by dendritic cells induces upregulation of scavengerreceptors, maturation and differentiation. Atherosclerosis. (2009) 205:44250. doi: 10.1016/j.atherosclerosis.2009.01.002

46. Sawamura T, Kume N, Aoyama T, Moriwaki H, Hoshikawa H, Aiba Y, et al. An endothelial receptor for oxidized low-density lipoprotein. Nature. (1997) 386:73-7. doi: 10.1038/386073a0

47. Yoshida H, Kondratenko N, Green S, Steinberg D, Quehenberger O. Identification of the lectin-like receptor for oxidized low-density lipoprotein in human macrophages and its potential role as a scavenger receptor. Biochem J. (1998) 334:9-13. doi: 10.1042/bj3340009

48. Joo HM, Li D, Dullaers M, Kim TW, Duluc D, Upchurch K, et al. C-Type lectin-like receptor LOX-1 promotes dendritic cell-mediated class-switched B cell responses. Immunity. (2014) 41:592-604. doi: 10.1016/j.immuni.2014.09.009

49. Aoyama T, Chen M, Fujiwara H, Masaki T, Sawamura T. LOX-1 mediates lysophosphatidylcholine-induced oxidized LDL uptake in smooth muscle cells. FEBS Lett. (2000) 467:217-20. doi: 10.1016/S0014-5793(00)01154-6

50. Draude G, Lorenz RL. TGF- $\beta 1$ downregulates CD36 and scavenger receptor a but upregulates LOX-1 in human macrophages. Am J Physiol Circ Physiol. (2000) 278:H1042-8. doi: 10.1152/ajpheart.2000.278.4.H1042

51. Delneste Y, Magistrelli G, Gauchat J-F, Haeuw J-F, Aubry J-P, Nakamura K, et al. Involvement of LOX-1 in dendritic cellmediated antigen cross-presentation. Immunity. (2002) 17:353-62. doi: 10.1016/S1074-7613(02)00388-6

52. Murphy JE, Vohra RS, Dunn S, Holloway ZG, Monaco AP, HomerVanniasinkam S, et al. Oxidised LDL internalisation by the LOX-1 scavenger receptor is dependent on a novel cytoplasmic motif and is regulated by dynamin-2. J Cell Sci. (2008) 121:2136-47. doi: 10.1242/jcs.020917

53. Jeannin P, Bottazzi B, Sironi M, Doni A, Rusnati M, Presta M, et al. Complexity and complementarity of outer membrane protein a recognition by cellular and humoral innate immunity receptors. Immunity. (2005) 22:551-60. doi: 10.1016/j.immuni.2005.03.008

54. Morawietz H, Rueckschloss U, Niemann B, Duerrschmidt N, Galle J, Hakim K, et al. Angiotensin II induces LOX-1, the human endothelial receptor for oxidized low-density lipoprotein. Circulation. (1999) 100:899902. doi: 10.1161/01.CIR.100.9.899 
55. Morawietz H, Duerrschmidt N, Niemann B, Galle J, Sawamura T, Holtz J. Induction of the OxLDL receptor LOX-1 by endothelin-1 in human endothelial cells. Biochem Biophys Res Commun. (2001) 284:961-5. doi: 10.1006/bbrc.2001.5044

56. Pérez L, Vallejos A, Echeverria C, Varela D, Cabello-Verrugio C, Simon F. OxHDL controls LOX-1 expression and plasma membrane localization through a mechanism dependent on NOX/ROS/NF$\kappa \mathrm{B}$ pathway on endothelial cells. Lab Invest. (2019) 99:421-37. doi: 10.1038/s41374-018-0151-3

57. Oka K, Sawamura T, Kikuta K, Itokawa S, Kume N, Kita T, et al. Lectinlike oxidized low-density lipoprotein receptor 1 mediates phagocytosis of aged/apoptotic cells in endothelial cells. Proc Natl Acad Sci USA. (1998) 95:9535-40. doi: 10.1073/pnas.95.16.9535

58. Chen M, Nagase M, Fujita T, Narumiya S, Masaki T, Sawamura T. Diabetes enhances lectin-like oxidized LDL Receptor-1 (LOX-1) expression in the vascular endothelium: possible role of LOX-1 ligand and AGE. Biochem Biophys Res Commun. (2001) 287:962-8. doi: 10.1006/bbrc.2001.5674

59. Shimaoka T, Kume N, Minami M, Hayashida K, Sawamura T, Kita T, et al. LOX-1 supports adhesion of gram-positive and gram-negative bacteria. $J$ Immunol. (2001) 166:5108-14. doi: 10.4049/jimmunol.166.8.5108

60. Xie J, Zhu H, Guo L, Ruan Y, Wang L, Sun L, et al. Lectin-like oxidized lowdensity lipoprotein receptor-1 delivers heat shock protein 60-fused antigen into the MHC class I presentation pathway. J Immunol. (2010) 185:2306-13. doi: 10.4049/jimmunol.0903214

61. Kakutani M, Masaki T, Sawamura T. A platelet-endothelium interaction mediated by lectin-like oxidized low-density lipoprotein receptor-1. Proc Natl Acad Sci USA. (2000) 97:360-4. doi: 10.1073/pnas.97.1.360

62. Smirnova IV, Kajstura M, Sawamura T, Goligorsky MS. Asymmetric dimethylarginine upregulates LOX-1 in activated macrophages: role in foam cell formation. Am J Physiol Hear Circ Physiol. (2004) 287:H782-90. doi: 10.1152/ajpheart.00822.2003

63. Mentrup T, Theodorou K, Cabrera-Cabrera F, Helbig AO, Happ K, Gijbels M, et al. Atherogenic LOX-1 signaling is controlled by SPPL2mediated intramembrane proteolysis. J Exp Med. (2019) 216:807-30. doi: 10.1084/jem.20171438

64. Hashimoto K, Oda Y, Nakamura F, Kakinoki R, Akagi M. Lectin-like, oxidized low-density lipoprotein receptor-1-deficient mice show resistance to age-related knee osteoarthritis. Eur J Histochem. (2017) 61:2762. doi: 10.4081/ejh.2017.2762

65. de Vries MA, Klop B, Janssen HW, Njo TL, Westerman EM, Castro Cabezas M. Postprandial inflammation: targeting glucose and lipids. Adv Exp Med Biol. (2014) 824:161-70. doi: 10.1007/978-3-319-07320-0_12

66. Shiu SW, Wong Y, Tan KC. Effect of advanced glycation end products on lectin-like oxidized low density lipoprotein receptor-1 expression in endothelial cells. J Atheroscler Thromb. (2012) 19:1083-92. doi: $10.5551 /$ jat.11742

67. Murase T, Kume N, Kataoka H, Minami M, Sawamura T, Masaki $\mathrm{T}$, et al. Identification of soluble forms of lectin-like oxidized LDL receptor-1. Arterioscler Thromb Vasc Biol. (2000) 20:715-20. doi: 10.1161/01.ATV.20.3.715

68. Tan KC, Shiu SW, Wong Y, Leng L, Bucala R. Soluble lectin-like oxidized low density lipoprotein receptor-1 in type 2 diabetes mellitus. J Lipid Res. (2008) 49:1438-44. doi: 10.1194/jlr.M700551-JLR200

69. Li C, Zhang J, Wu H, Li L, Yang C, Song S, et al. Lectin-like oxidized lowdensity lipoprotein receptor-1 facilitates metastasis of gastric cancer through driving epithelial-mesenchymal transition and PI3K/Akt/GSK3 $\beta$ activation. Sci Rep. (2017) 7:45275. doi: 10.1038/srep45275

70. Murdocca M, Mango R, Pucci S, Biocca S, Testa B, Capuano R, et al. The lectin-like oxidized LDL receptor-1: a new potential molecular target in colorectal cancer. Oncotarget. (2016) 7:14765-80. doi: 10.18632/oncotarget.7430

71. González-Chavarría I, Cerro RP, Parra NP, Sandoval FA, Zuñiga FA, Omazábal VA, et al. Lectin-like oxidized LDL receptor-1 is an enhancer of tumor angiogenesis in human prostate cancer cells. PLoS ONE. (2014) 9:e106219. doi: 10.1371/journal.pone.0106219

72. Liang M, Zhang P, Fu J. Up-regulation of LOX-1 expression by TNF- $\alpha$ promotes trans-endothelial migration of MDA-MB-231 breast cancer cells. Cancer Lett. (2007) 258:31-7. doi: 10.1016/j.canlet.2007.08.003
73. Condamine T, Gabrilovich DI, Dominguez GA, Youn J-I, Kossenkov AV, Mony S, et al. Lectin-type oxidized LDL receptor-1 distinguishes population of human polymorphonuclear myeloid-derived suppressor cells in cancer patients. Sci Immunol. (2016) 1:aaf8943. doi: 10.1126/sciimmunol.aaf8943

74. Parlato S, Romagnoli G, Spadaro F, Canini I, Sirabella P, Borghi P, et al. LOX-1 as a natural IFN- $\alpha$-mediated signal for apoptotic cell uptake and antigen presentation in dendritic cells. Blood. (2010) 115:1554-63. doi: 10.1182/blood-2009-07-234468

75. Lobato-Pascual A, Saether PC, Fossum S, Dissen E, Daws MR. Mincle, the receptor for mycobacterial cord factor, forms a functional receptor complex with MCL and FceRI- $\gamma$. Eur J Immunol. (2013) 43:3167-74. doi: 10.1002/eji.201343752

76. Matsumoto M, Tanaka T, Kaisho T, Sanjo H, Copeland NG, Gilbert DJ, et al. A novel LPS-inducible C-type lectin is a transcriptional target of NF-IL6 in macrophages. J Immunol. (1999) 163:5039-48.

77. Ichioka M, Suganami T, Tsuda N, Shirakawa I, Hirata Y, Satoh-Asahara $\mathrm{N}$, et al. Increased expression of macrophage-inducible C-type lectin in adipose tissue of obese mice and humans. Diabetes. (2011) 60:819-26. doi: $10.2337 / \mathrm{db} 10-0864$

78. Lv LL, Tang PM-KK, Li CJ, You YK, Li J, Huang X-RR, et al. The pattern recognition receptor, Mincle, is essential for maintaining the M1 macrophage phenotype in acute renal inflammation. Kidney Int. (2017) 91:587-602. doi: 10.1016/j.kint.2016.10.020

79. Miyake Y, Masatsugu O, Yamasaki S. C-Type lectin receptor MCL facilitates mincle expression and signaling through complex formation. J Immunol. (2015) 194:5366-74. doi: 10.4049/jimmunol.1402429

80. Greco SH, Mahmood SK, Vahle A-K, Ochi A, Batel J, Deutsch M, et al. Mincle suppresses Toll-like receptor 4 activation. J Leukoc Biol. (2016) 100:185-94. doi: 10.1189/jlb.3A0515-185R

81. Greco SH, Torres-Hernandez A, Kalabin A, Whiteman C, Rokosh R, Ravirala $\mathrm{S}$, et al. Mincle signaling promotes con a hepatitis. J Immunol. (2016) 197:2816-27. doi: 10.4049/jimmunol.1600598

82. Kostarnoy AV, Gancheva PG, Lepenies B, Tukhvatulin AI, Dzharullaeva AS, Polyakov NB, et al. Receptor Mincle promotes skin allergies and is capable of recognizing cholesterol sulfate. Proc Natl Acad Sci USA. (2017) 114:E2758-65. doi: 10.1073/pnas.1611665114

83. Suzuki Y, Nakano Y, Mishiro K, Takagi T, Tsuruma K, Nakamura M, et al. Involvement of Mincle and Syk in the changes to innate immunity after ischemic stroke. Sci Rep. (2013) 3:3177. doi: 10.1038/srep03177

84. de Rivero Vaccari JC, Brand FJ, Berti AF, Alonso OF, Bullock MR, de Rivero Vaccari JP. Mincle signaling in the innate immune response after traumatic brain injury. J Neurotrauma. (2015) 32:228-36. doi: 10.1089/neu.2014.3436

85. Nakamura N, Shimaoka Y, Tougan T, Onda H, Okuzaki D, Zhao H, et al. Isolation and expression profiling of genes upregulated in bone marrowderived mononuclear cells of rheumatoid arthritis patients. DNA Res. (2006) 13:169-83. doi: 10.1093/dnares/dsl006

86. N'diaye M, Brauner S, Flytzani S, Kular L, Warnecke A, Adzemovic MZ, et al. C-type lectin receptors $\mathrm{Mcl}$ and Mincle control development of multiple sclerosis-like neuroinflammation. J Clin Invest. (2019) 30:838-52. doi: 10.1172/JCI125857

87. Wu XY, Guo JP, Yin FR, Lu XL, Li R, He J, et al. Macrophage-inducible C-type lectin is associated with anti-cyclic citrullinated peptide antibodiespositive rheumatoid arthritis in men. Chin Med J. (2012) 125:3115-9. doi: 10.3760/cma.j.issn.0366-6999.2012.17.027

88. Ishikawa E, Ishikawa T, Morita YS, Toyonaga K, Yamada H, Takeuchi $\mathrm{O}$, et al. Direct recognition of the mycobacterial glycolipid, trehalose dimycolate, by C-type lectin Mincle. J Exp Med. (2009) 206:2879-88. doi: 10.1084/jem.20091750

89. Das BK, Xia L, Palandjian L, Gozani O, Chyung Y, Reed R. Characterization of a protein complex containing spliceosomal proteins SAPs 49, 130, 145, and 155. Mol Cell Biol. (1999) 19:6796-802. doi: 10.1128/MCB.19.10.6796

90. Nagata M, Izumi Y, Ishikawa E, Kiyotake R, Doi R, Iwai S, et al. Intracellular metabolite $\beta$-glucosylceramide is an endogenous Mincle ligand possessing immunostimulatory activity. Proc Natl Acad Sci USA. (2017) 114:E3285-94. doi: 10.1073/pnas.1618133114

91. Kiyotake R, Oh-Hora M, Ishikawa E, Miyamoto T, Ishibashi T, Yamasaki S. Human Mincle binds to cholesterol crystals and triggers innate immune responses. J Biol Chem. (2015) 290:25322-32. doi: 10.1074/jbc.M115.645234 
92. Honjoh C, Chihara K, Yoshiki H, Yamauchi S, Takeuchi K, Kato Y, et al. Association of C-Type lectin Mincle with FceRI $\beta \gamma$ subunits leads to functional activation of RBL-2H3 cells through Syk. Sci Rep. (2017) 7:46064. doi: 10.1038/srep46064

93. Lee WB, Kang JS, Yan JJ, Lee MS, Jeon BY, Cho SN, Kim YJ. Neutrophils promote mycobacterial trehalose dimycolate-induced lung inflammation via the mincle pathway. PLoS Pathog. (2012) 8:e1002614. doi: 10.1371/journal.ppat.1002614

94. Lee WB, Kang JS, Choi WY, Zhang Q, Kim CH, Choi UY, et al. Mincle-mediated translational regulation is required for strong nitric oxide production and inflammation resolution. Nat Commun. (2016) 7:1-14. doi: $10.1038 /$ ncomms11322

95. Werninghaus K, Babiak A, Gross O, Hölscher C, Dietrich H, Agger EM, et al. Adjuvanticity of a synthetic cord factor analogue for subunit Mycobacterium tuberculosis vaccination requires FcRgamma-Syk-Card9-dependent innate immune activation. J Exp Med. (2009) 206:89-97. doi: 10.1084/jem.200 81445

96. Schoenen H, Bodendorfer B, Hitchens K, Manzanero S, Werninghaus K, Nimmerjahn F, et al. Cutting edge: Mincle is essential for recognition and adjuvanticity of the mycobacterial cord factor and its synthetic analog trehalose-dibehenate. J Immunol. (2010) 184:2756-60. doi: 10.4049/jimmunol.0904013

97. Patin EC, Orr SJ, Schaible UE. Macrophage inducible C-Type lectin as a multifunctional player in immunity. Front Immunol. (2017) 8:861. doi: 10.3389/fimmu.2017.00861

98. Kataoka H, Kono H, Patel Z, Rock KL. Evaluation of the contribution of multiple DAMPs and DAMP receptors in cell death-induced sterile inflammatory responses. PLoS ONE. (2014) 9:e104741. doi: 10.1371/journal.pone.0104741

99. Strissel KJ, Stancheva Z, Miyoshi H, Perfield JW, DeFuria J, Jick Z, et al. Adipocyte death, adipose tissue remodeling, and obesity complications. Diabetes. (2007) 56:2910-8. doi: 10.2337/db07-0767

100. Cinti S, Mitchell G, Barbatelli G, Murano I, Ceresi E, Faloia E, et al. Adipocyte death defines macrophage localization and function in adipose tissue of obese mice and humans. J Lipid Res. (2005) 46:2347-55. doi: 10.1194/jlr.M500294-JLR200

101. Ishikawa A, Miyake Y, Kobayashi K, Murata Y, Iizasa S, Iizasa E, et al. Essential roles of C-type lectin Mincle in induction of neuropathic pain in mice. Sci Rep. (2019) 9:872. doi: 10.1038/s41598-018-37318-8

102. Seifert L, Werba G, Tiwari S, Giao Ly NN, Alothman S, Alqunaibit $\mathrm{D}$, et al. The necrosome promotes pancreatic oncogenesis via CXCL1 and Mincle-induced immune suppression. Nature. (2016) 532:245-9. doi: 10.1038/nature17403

103. Iborra S, Martínez-López M, Cueto FJ, Conde-Garrosa R, Del Fresno C, Izquierdo HM, et al. Leishmania uses Mincle to target an inhibitory ITAM signaling pathway in dendritic cells that dampens adaptive immunity to infection. Immunity. (2016) 45:788-801. doi: 10.1016/j.immuni.2016. 09.012

104. Wevers BA, Kaptein TM, Zijlstra-Willems EM, Theelen B, Boekhout T, Geijtenbeek TB, et al. Fungal engagement of the C-Type lectin Mincle suppresses Dectin-1-induced antifungal immunity. Cell Host Microbe. (2014) 15:494-505. doi: 10.1016/j.chom.2014.03.008

105. Neumann K, Castiñeiras-Vilariño M, Höckendorf U, Hannesschläger N, Lemeer S, Kupka D, et al. Clec12a is an inhibitory receptor for uric acid crystals that regulates inflammation in response to cell death. Immunity. (2014) 40:389-99. doi: 10.1016/j.immuni.2013.12.015

106. Hutten TJ, Thordardottir S, Fredrix H, Janssen L, Woestenenk R, Tel J, et al. CLEC12A-mediated antigen uptake and cross-presentation by human dendritic cell subsets efficiently boost tumor-reactive $\mathrm{T}$ cell responses. $J$ Immunol. (2016) 197:2715-25. doi: 10.4049/jimmunol.1600011

107. Hao L, Klein J, Nei M. Heterogeneous but conserved natural killer receptor gene complexes in four major orders of mammals. Proc Natl Acad Sci USA. (2006) 103:3192-7. doi: 10.1073/pnas.0511280103

108. Marshall AS, Willment JA, Pyz E, Dennehy KM, Reid DM, Dri P, et al. Human MICL (CLEC12A) is differentially glycosylated and is downregulated following cellular activation. Eur J Immunol. (2006) 36:2159-69. doi: 10.1002/eji.200535628
109. Chen C-H, Floyd H, Olson NE, Magaletti D, Li C, Draves K, et al Dendritic-cell-associated C-type lectin 2 (DCAL-2) alters dendriticcell maturation and cytokine production. Blood. (2006) 107:1459-67. doi: 10.1182/blood-2005-08-3264

110. Lahoud MH, Proietto AI, Ahmet F, Kitsoulis S, Eidsmo L, Wu L, et al. The CType lectin Clec12A present on mouse and human dendritic cells can serve as a target for antigen delivery and enhancement of antibody responses. $J$ Immunol. (2009) 182:7587-94. doi: 10.4049/jimmunol.0900464

111. Morsink LM, Walter RB, Ossenkoppele GJ. Prognostic and therapeutic role of CLEC12A in acute myeloid leukemia. Blood Rev. (2019) 34:26-33. doi: 10.1016/j.blre.2018.10.003

112. Pyz E, Huysamen C, Marshall AS, Gordon S, Taylor PR, Brown GD. Characterisation of murine MICL (CLEC12A) and evidence for an endogenous ligand. Eur J Immunol. (2008) 38:1157-63. doi: 10.1002/eji.200738057

113. Gagné V, Marois L, Levesque J-M, Galarneau H, Lahoud MH, Caminschi $\mathrm{I}$, et al. Modulation of monosodium urate crystal-induced responses in neutrophils by the myeloid inhibitory C-type lectin-like receptor: potential therapeutic implications. Arthritis Res Ther. (2013) 15:R73. doi: 10.1186/ar4250

114. Redelinghuys P, Whitehead L, Augello A, Drummond RA, Levesque JM, Vautier S, et al. MICL controls inflammation in rheumatoid arthritis. Ann Rheum Dis. (2016) 75:1386-91. doi: 10.1136/annrheumdis-2014-206644

115. Li K, Neumann K, Duhan V, Namineni S, Hansen AL, Wartewig T, et al. The uric acid crystal receptor Clec12A potentiates type I interferon responses. Proc Natl Acad Sci USA. (2019) 201821351. doi: 10.1073/pnas.1821351116

116. Wilson EB, Yamada DH, Elsaesser H, Herskovitz J, Deng J, Cheng G, et al. Blockade of chronic type I interferon signaling to control persistent LCMV infection. Science. (2013) 340:202-7. doi: 10.1126/science.1235208

117. Teijaro JR, Ng C, Lee AM, Sullivan BM, Sheehan KC, Welch M, et al. Persistent LCMV infection is controlled by blockade of type I interferon signaling. Science. (2013) 340:207-11. doi: 10.1126/science.1235214

118. Troegeler A, Mercier I, Cougoule C, Pietretti D, Colom A, Duval C, et al. Ctype lectin receptor DCIR modulates immunity to tuberculosis by sustaining type I interferon signaling in dendritic cells. Proc Natl Acad Sci USA. (2017) 114:E540-9. doi: 10.1073/pnas.1613254114

119. Crozat K, Tamoutounour S, Vu Manh T-P, Fossum E, Luche H, Ardouin $\mathrm{L}$, et al. Cutting edge: expression of XCR1 defines mouse lymphoid-tissue resident and migratory dendritic cells of the CD8 $\alpha+$ Type. J Immunol. (2011) 187:4411-5. doi: 10.4049/jimmunol.1101717

120. Gurka S, Hartung E, Becker M, Kroczek RA. Mouse conventional dendritic cells can be universally classified based on the mutually exclusive expression of XCR1 and SIRP $\alpha$. Front Immunol. (2015) 6:35. doi: 10.3389/fimmu.2015.00035

121. Schraml BU, Van Blijswijk J, Zelenay S, Whitney PG, Filby A, Acton SE, et al. Genetic tracing via DNGR-1 expression history defines dendritic cells as a hematopoietic lineage. Cell. (2013) 154:843-58. doi: 10.1016/j.cell.2013.07.014

122. Schreibelt G, Klinkenberg LJ, Cruz LJ, Tacken PJ, Tel J, Kreutz M, et al. The C-type lectin receptor CLEC9A mediates antigen uptake and (cross-)presentation by human blood BDCA3 myeloid dendritic cells. Blood. (2012) 119:2284-92. doi: 10.1182/blood-2011-08-373944

123. Huysamen C, Willment JA, Dennehy KM, Brown GD. CLEC9A is a novel activation C-type lectin-like receptor expressed on BDCA3+ dendritic cells and a subset of monocytes. J Biol Chem. (2008) 283:16693-701. doi: 10.1074/jbc.M709923200

124. Sancho D, Mourão-Sá D, Joffre OP, Schulz O, Rogers NC, Pennington DJ, et al. Tumor therapy in mice via antigen targeting to a novel, DC-restricted C-type lectin. J Clin Invest. (2008) 118:2098-110. doi: 10.1172/JCI34584

125. Hanč P, Fujii T, Iborra S, Yamada Y, Huotari J, Schulz O, et al. Structure of the complex of F-Actin and DNGR-1, a C-Type lectin receptor involved in dendritic cell cross-presentation of dead cell-associated antigens. Immunity. (2015) 42:839-49. doi: 10.1016/j.immuni.2015.04.009

126. Ahrens S, Zelenay S, Sancho D, Hanč P, Kjær S, Feest C, et al. FActin is an evolutionarily conserved damage-associated molecular pattern recognized by DNGR-1, a receptor for dead cells. Immunity. (2012) 36:63545. doi: 10.1016/j.immuni.2012.03.008 
127. Zelenay S, Keller AM, Whitney PG, Schraml BU, Deddouche S, Rogers NC, et al. The dendritic cell receptor DNGR-1 controls endocytic handling of necrotic cell antigens to favor cross-priming of CTLs in virus-infected mice. J Clin Invest. (2012) 122:1615-27. doi: 10.1172/JCI60644

128. Schulz O, Hanč P, Böttcher JP, Hoogeboom R, Diebold SS, Tolar P, et al. Myosin II synergizes with F-Actin to promote DNGR-1-dependent crosspresentation of dead cell-associated antigens. Cell Rep. (2018) 24:419-28. doi: 10.1016/j.celrep.2018.06.038

129. Iborra S, Izquierdo HM, Martínez-López M, Blanco-Menéndez N, Reis e Sousa C, Sancho D. The DC receptor DNGR-1 mediates cross-priming of CTLs during vaccinia virus infection in mice. J Clin Invest. (2012) 122:162843. doi: $10.1172 /$ JCI60660

130. Iborra S, Martínez-López M, Khouili SC, Enamorado M, Cueto FJ, Conde-Garrosa R, et al. Optimal generation of tissue-resident but not circulating memory $\mathrm{T}$ Cells during viral infection requires crosspriming by DNGR-1+ dendritic cells. Immunity. (2016) 45:847-60. doi: 10.1016/j.immuni.2016.08.019

131. Haddad Y, Lahoute C, Clément M, Laurans L, Metghalchi S, Zeboudj L, et al. The dendritic cell receptor DNGR-1 promotes the development of atherosclerosis in mice. Circ Res. (2017) 121:234-43. doi: 10.1161/CIRCRESAHA.117.310960

132. del Fresno C, Saz-Leal P, Enamorado M, Wculek SK, Martínez-Cano $\mathrm{S}$, Blanco-Menéndez $\mathrm{N}$, et al. DNGR-1 in dendritic cells limits tissue damage by dampening neutrophil recruitment. Science. (2018) 362:351-6. doi: $10.1126 /$ science.aan 8423

133. Zelenay S, Reis e Sousa C. Adaptive immunity after cell death. Trends Immunol. (2013) 34:329-35. doi: 10.1016/j.it.2013.03.005
134. Radogna F, Diederich M. Stress-induced cellular responses in immunogenic cell death: Implications for cancer immunotherapy. Biochem Pharmacol. (2018) 153:12-23. doi: 10.1016/j.bcp.2018. 02.006

135. Aleynick M, Svensson-Arvelund J, Flowers CR, Marabelle A, Brody JD. Pathogen molecular pattern receptor agonists: treating cancer by mimicking infection. Clin Cancer Res. (2019) 25:1800. doi: 10.1158/1078-0432.CCR-18-1800

136. Aretz J, Wamhoff E-C, Hanske J, Heymann D, Rademacher C. Computational and experimental prediction of human C-type lectin receptor druggability. Front Immunol. (2014) 5:323. doi: 10.3389/fimmu.2014. 00323

Conflict of Interest: MD was employed by the company OSE Immunotherapeutics.

The remaining authors declare that the research was conducted in the absence of any commercial or financial relationships that could be construed as a potential conflict of interest.

Copyright (๑) 2020 Drouin, Saenz and Chiffoleau. This is an open-access article distributed under the terms of the Creative Commons Attribution License (CC BY). The use, distribution or reproduction in other forums is permitted, provided the original author(s) and the copyright owner(s) are credited and that the original publication in this journal is cited, in accordance with accepted academic practice. No use, distribution or reproduction is permitted which does not comply with these terms. 